ISSN: 2224-0616

Int. J. Agril. Res. Innov. \& Tech. 3 (1): 52-59, J une, 2013 Available online at http:// www.ijarit.webs.com

\title{
EVALUATION OF RICE GERMPLASM UNDER SALT STRESS AT THE SEEDLING STAGE THROUGH SSR MARKERS
}

\author{
M. Al-Amin', M.M. Islam², S.N. Begum ${ }^{3}$, M.S. Alam1, M. Moniruzzaman', M.A.K. Patwary1
}

Received 30 April 2013, Revised 30 May 2013, Accepted 20 June 2013, Published online 30 June 2013

\begin{abstract}
Twenty eight rice germplasms were used for identification of salt tolerant rice genotypes at the seedling stage at the experimental farm and Biotechnology laboratory of the Bangladesh Institute of Nuclear Agriculture (BINA), Mymensingh during February 2009 to October 2009. Phenotyping for salinity screening of the rice genotypes was done using salinized (EC level $12 \mathrm{dS} \mathrm{m}^{-1}$ ) nutrient solution in hydroponic system. Genotypes were evaluated for salinity tolerance on 1-9 scale based on seedling growth parameters following modified Standard Evaluation Scoring (SES) of IRRI. Phenotypically, on the basis of SES and \% total dry matter (TDM) reduction of the genotypes viz. PBSAL-614, PBSAL-613, PBSAL-730, Horkuch, S-478/3 Pokkali and PBSAL (STL)-15 were found to be salt tolerant; on the other hand Iratom-24, S-653/32, S-612/32, S-604/32, S-633/32, Charnock (DA6), BINA Dhan-6 and S-608/32 were identified as salt susceptible. For genotyping, ten SSR markers were used for polymorphism, where 3 primers (RM127, RM443 and RM140) were selected for evaluation of salt tolerance. In respect of Primer RM127, 7 lines were found salt tolerant and 11 lines were moderately tolerant and 10 lines were susceptible. Nine tolerant, 9 moderately tolerant and 10 susceptible lines were found when the primer RM140 was used and primer RM443 identified 8 lines as tolerant, 9 lines as moderately tolerant and 11 lines as susceptible. Thus, the salt tolerant lines can be used in further evaluation for salinity tolerance and the SSR markers used in this study are proving valuable for identifying salt tolerant genes in marker assisted breeding.
\end{abstract}

Keywords: Rice, Salinity Tolerance, SSR Markers, Seedling Stage, Polymorphism

${ }^{1}$ Department of Genetics and Plant Breeding, Bangladesh Agricultural University, Mymensingh 2202, Bangladesh

${ }^{2}$ Biotechnology Division, Bangladesh Institute of Nuclear Agriculture (BINA), BAU Campus, Mymensingh 2202

${ }^{3}$ Plant Breeding Division, Bangladesh Institute of Nuclear Agriculture (BINA), BAU Campus, Mymensingh- 2202

*Corresponding author's email: asarowar04bau@gmail.com (M.S. Alam)

\section{Introduction}

Rice (Oryza sativa L.) belongs to the family Gramineae. It is the staple food crop in Bangladesh and one of the most important cereal crops throughout the world. This staple food ranked first position by production (28931 thousand metric tons) during the year 2007-08 among all cereals in Bangladesh (BBS, 2009). Total rice cultivated area 10575 thousand hectares. One of such efforts is to cultivate rice with elevated level of salt tolerance on salt affected marginal lands. Over 30 percent of the net cultivable area of Bangladesh lies in the coastal zone. Out of 2.85 million hectares of coastal and offshore land, about 1.5 million hectares are affected by varying degrees of salinity. The coastal saline soils are distributed unevenly in 64 Upazila of 13 District, covering portions of eight agro-ecological zones (AEZ) of the country (Seraj and Salam, 2000). Salinity affects plants at all stages of development, but sensitivity sometimes varies from growth stage to the next. Several studies indicated that rice is tolerant during germination, becomes very sensitive during early seedling stage (2-3 leaf stage), gains tolerance during vegetative growth stage becomes sensitive during pollination and fertilization and then become increasingly more tolerant at maturity (Pearson et al., 1966; IRRI, 1967). However, some studies reported that at fertilization, rice is not sensitive to salinity (Kaddah et al., 1975). Hence, early seedling stages were used to know the response of the rice plant to salinity. To screen the salt tolerant variety, we need reliable technique. IRRI standard protocol for salinity screening is such type of technique (Gregorio, 1997). Conventional breeding is time consuming and depends on environmental conditions. Molecular marker technology offers a possibility by adopting a wide range of novel approaches to improve the selection strategies in rice breeding. SSR or microsatellite markers are proved to be ideal for making genetic maps (Islam, 2004; Niones, 2004), assisting selection (Bhuiyan, 2005) and studying genetic diversity in germplasm. 
Microsatellite marker analysis is promising to identify major gene locus for salt tolerance that can be helpful for plant breeders to develop new cultivars. From these points of view the present study were undertaken for determine the phenotypic performance of rice germplasm under salinized conditions at the seedling stage and to identify salt tolerant rice lines from twenty eight rice germplasm using SSR markers.

\section{Materials and Methods}

\section{Plant materials}

The experiment was carried out at the experimental farm and Biotechnology Laboratory of the Bangladesh Institute of Nuclear Agriculture (BINA), Mymensingh from February 2009 to October 2009. In this study twenty eight rice germplasm were used for salinity screening at the seedling stage following International Rice Research Institute (IRRI) standard protocol (Gregorio et al., 1997). These germplasms were collected from different sources like, International Rice Gene bank (IRG) of International Rice Research Institute (IRRI), Philippines, Bangladesh Rice Research Institute (BRRI), Bangladesh Institute of Nuclear Agriculture (BINA), Mymensingh. Twenty eight rice germplasm (Horkuch, Charnock, Keshrail, Iratom-24, BRRI dhan-40, Binadhan-6, PBSAL(STL)-15, PBSAL-613, PBSAL-614, PBSAL-730, PBSAL-656, STM-1, PBRC(STL)-20, S-530/32, S-603/32, S-604/32, S-445/32, S$611 / 32, \quad \mathrm{~S}-612 / 32, \quad \mathrm{~S}-546 / 32, \mathrm{~S}-653 / 32, \mathrm{~S}-$ $635 / 32$, S-375/32, S-731/32, S-478/32, S608/32, S633/32 and Pokkali ) were evaluated for salinity screening.

\section{Phenotypic study of salinity tolerance at seedling stage}

The screening for salt tolerance were done using modified standard evaluation score (SES) of visual salt injury of the seedlings (Table 1).

Hydroponic system with IRRI standard protocol (Gregorio et al., 1997) was used at the glasshouse to evaluate salt tolerance of rice germplasm. Nutrient solution (Yoshida et al., 1976) was used in hydroponic system for screening salinity tolerance at the seedling stage. The modified standard evaluation score (SES) of IRRI was used to assess the visual symptoms of salt toxicity (Table 1). This scoring discriminates the tolerant, moderately tolerant and susceptible rice lines.

Table 1. Modified standard evaluation score (SES) of visual salt injury at seedling stage (Method adapted from Gregorio et al. (1997)

\begin{tabular}{lll}
\hline Score & Observation & Response category \\
\hline 1 & Normal growth, no leaf symptoms & Highly tolerant \\
3 & Nearly normal growth, but leaf tips of few leaves whitish and rolled & Tolerant \\
5 & Growth severely retarded, most leaves rolled; only a few are & Moderately tolerant \\
& elongating & \\
7 & Complete cessation of growth; most leaves dry; some plants dying & Susceptible \\
9 & Almost all plants dead or dying & Highly susceptible \\
\hline
\end{tabular}

\section{CTAB mini preparation DNA extraction}

The modified Cetyl Trimethyl Ammonium Bromide (CTAB) mini-prep method was used to extract DNA from the plant leaves. The following steps were followed in PCR-based DNA marker analysis. Healthy leaf samples were collected from 25-day old seedlings of each germplasm for isolation of genomic DNA. Leaf sample was washed in distilled water and ethanol. The collected leaf samples were then put into polythene bags with tags, placed on ice and stored in a $-80 \mathrm{oC}$ freezer. The leaf samples were ground with pestle and mortar to collect DNA. Strict hygiene was maintained during the DNA extraction by autoclaving all glassware, micropipette tips, PCR tubes, distilled water, reagents and buffer solutions.

Isolated genomic DNA contains a large amount of RNA and pigments, which cause over estimation of DNA concentration during spectrophotometer reading. Therefore, the DNA samples were evaluated qualitatively using agarose gel electrophoresis. For checking of DNA concentration, two methods can be applied: 1) $\lambda$
DNA and 2) Spectrophotometry. For this study only $\lambda$ DNA was used. After electrophoresis, the gel was taken out carefully from the gel chamber and transferred in a prepared ethidium bromide solution for staining. Staining was done for 20 minutes and then placed on the UV transilluminator in the dark chamber of the Image Documentation System.

\section{Amplification of microsatellite markers and evaluation of genotypes}

Ten primers of random sequence were selected for amplification of the DNA sequences. Primers were evaluated based on intensity of bands, consistency within individual, presence of smearing and potential for population discrimination. In this experiment, OSR14, OSR17 RM152, RM443, RM127, RM140, RM9, RM169, RM18 and RM21 primers were used for polymorphism. Out of ten primers, three polymorphic SSR markers viz., RM127, RM443 and RM140 were selected to evaluate 28 rice germplasm for salt tolerance. 
Table 2. The sequence and size of the microsatellite markers used for the study

\begin{tabular}{llccc}
\hline Primer & \begin{tabular}{l} 
PCR \\
product \\
\cline { 3 - 4 }
\end{tabular} & \multicolumn{2}{c}{ Sequence } & Annealing \\
\cline { 3 - 4 } & Fize $(\mathrm{bp})$ & & Reverse & \\
\hline RM443 & $118-124$ & GATGGTTTTCATCGGCTACG & AGTCCCAGAATGTCGCTTCG & 55 \\
RM127 & $209-226$ & GTGGGATAGCTGCGTCG & AGGCCAGGGTGTTGGCATGCTG & 55 \\
RM140 & $259-263$ & TGCCTCTTCCCTGGCTCCCCTG & GGCATGCCGAATGAAATGCATG & 55 \\
\hline
\end{tabular}

The PCR cocktail had total volume of $15.0 \mathrm{\mu l}$ reaction mixture including 2 pl DNA based on salinity protocol, was placed in the PCR tubes and run in the DNA thermal cycler. The PCR tubes were set on the wells of the thermocycler plate and the machine was run according to the programme.

The germplasms having similar banding pattern to Pokkali were considered as tolerant, banding pattern having similar to Iratom-24 were considered as salt susceptible and having banding pattern at the medium position between Pokkali and Iratom-24 were considered as medium tolerant In each marker, allelic bands were designated as $\mathrm{T}$ for tolerant, $\mathrm{S}$ for susceptible and MT for medium tolerant.

\section{Results and Discussion}

\section{Phenotypic variation of rice genotypes under salinized and non-salinized conditions at the seedling stage}

Twenty eight genotypes of rice seedlings were used for screening salinity tolerance. After two or three days of salinization, salt stress symptoms were started. Several salt injuries observed in the salinized conditions which were leaves became yellowish, drying of leaves, shoot growth reduction, root growth reduction, stem became thin and week, stunted growth of seedlings and seedling drying occurred. These symptoms were also observed by several researchers (Bhuiyan, 2005; Islam, 2004; Niones, 2004; Bonilla et al., 2002). The seedlings in the non-salinized condition showed normal growth over the salinized condition. Salt tolerant seedlings were distinguished from the sensitive seedlings when grown in salinized condition.

The salinity tolerant lines showed no symptom of salt injury. In the salinized setup, twenty eight germplasms showed wide variation in phenotypes under salt stress. Among the 28 germplasms, seven were found salt tolerant viz. Pokkali, Horkuch, PBSAL (STL)-15, PBSAL-613, PBSAL-730, PBSAL-656 and S-478/32 (Table.3), ten were moderately tolerant and eleven were susceptible. According to the SES of IRRI (Gregorio et al., 1997) a score from 1-9 was used for grading the genotypes based on visual salt injury where, $1=$ highly tolerant and $9=$ highly susceptible. This scoring differentiated the susceptible genotypes from the tolerant and moderately tolerant genotypes. Islam et al. (2007) also observed wide variation in phenotypes from tolerant (score 3) to highly susceptible (score 9) using modified SES of IRRI standard protocol.

Table 3. Performance of the germplasms under salinized condition (EC $12 \mathrm{dS} \mathrm{m}^{-1}$ ) at the seedling stage

\begin{tabular}{llcc}
\hline Sl. No. & Name of the Variety & SES Scoring & Tolerance \\
\hline 1 & S-611/32 & 5 & $\mathrm{MT}$ \\
2 & Keshrail & 5 & $\mathrm{MT}$ \\
3 & S-612/32 & 7 & $\mathrm{~S}$ \\
4 & S-546/32 & 5 & $\mathrm{MT}$ \\
5 & S-653/32 & 7 & $\mathrm{~S}$ \\
6 & BRRI dhan 40 & 7 & $\mathrm{~S}$ \\
7 & PBRC(STL)-20 & 5 & $\mathrm{MT}$ \\
8 & S-604/32 & 7 & $\mathrm{~S}$ \\
9 & S-530/32 & 5 & $\mathrm{MT}$ \\
10 & S-603/32 & 5 & $\mathrm{MT}$ \\
11 & S-445/32 & 5 & $\mathrm{MT}$ \\
12 & S-635/32 & 7 & $\mathrm{MT}$ \\
13 & S-375/32 & 5 & $\mathrm{~S}$ \\
14 & S-731/32 & 7 & $\mathrm{~T}$ \\
15 & PBRC(STL)-15 & 3 & $\mathrm{~T}$ \\
16 & Horkuch & 3 & $\mathrm{~T}$ \\
17 & PBSAL-613 & 3 & $\mathrm{~T}$ \\
18 & S-478/32 & 3 & $\mathrm{~S}$ \\
19 & Charnock(DA-6) & 7 & $\mathrm{~S}$ \\
20 & S-608/32 & 7 & $\mathrm{~T}$ \\
21 & PBSAL-656 & 3 & $\mathrm{~S}$ \\
22 & S-633/32 & 7 & \\
\hline
\end{tabular}




\begin{tabular}{lllc}
\hline 23 & Binadhan-6 & 7 & \\
24 & PBSAL-614 & 5 & $\mathrm{~S}$ \\
25 & STM-1 & 5 & $\mathrm{MT}$ \\
26 & PBSAL-730 & 3 & $\mathrm{MT}$ \\
27 & Pokkali & 3 & $\mathrm{~T}$ \\
28 & Iratom-24 & 7 & $\mathrm{~S}$ \\
\hline
\end{tabular}

$\mathrm{T}=$ tolerant, $\mathrm{MT}=$ moderately tolerant, $\mathrm{S}=$ susceptible

1-9 scale, where $1=$ highly tolerant and $9=$ highly susceptible

Rice plant showed various degrees of responses to S-653/32(60\%), Binadhan-6 (59.23\%), the salinity. The agronomic traits of tolerant lines (54.23\%), and BRRIdhan 40(53.43\%) showed shown lesser reduction than susceptible lines. The greater plant height reduction under the salinity plant height, root length and total dry matter are stress (at $12 \mathrm{dS} \mathrm{m}^{-1}$ ) (Table 4). greatly affected by the salinity. Iratom-28 (60.5),

Table 4. Performance of plant height, root length and total dry matter at the seedling stage (30DAS) under salinized and non-salinized conditions

\begin{tabular}{|c|c|c|c|c|c|c|c|c|c|c|}
\hline \multirow{2}{*}{$\begin{array}{l}\text { Sl. } \\
\text { No. }\end{array}$} & \multirow{2}{*}{ Genotypes } & \multicolumn{3}{|c|}{ Plant height (cm) } & \multicolumn{3}{|c|}{ Root length (cm) } & \multicolumn{3}{|c|}{ Total dry matter (g) } \\
\hline & & $\begin{array}{c}\text { Non- } \\
\text { salinized }\end{array}$ & Salinized & $\begin{array}{c}\% \\
\text { Reduction }\end{array}$ & $\begin{array}{c}\text { Non- } \\
\text { salinized }\end{array}$ & Salinized & $\begin{array}{c}\% \\
\text { Reductio }\end{array}$ & $\begin{array}{c}\text { Non- } \\
\text { salinized }\end{array}$ & Salinized & $\begin{array}{c}\% \\
\text { Reduction }\end{array}$ \\
\hline 1 & S-611/32 & 51.2 & 27.8 & 45.70 & 18.2 & 10.2 & 43.95 & 26.2 & 5 & 80.91 \\
\hline 2 & Keshrail & 56.2 & 43.8 & 22.06 & 18.6 & 12.8 & 31.18 & 25.4 & 14.2 & 44.09 \\
\hline 3 & S-612/32 & 44.4 & 24.6 & 44.59 & 15.8 & 12.4 & 21.51 & 10.6 & 4.4 & 58.49 \\
\hline 4 & S-546/ 32 & 49 & 23.6 & 51.83 & 17 & 14.8 & 12.94 & 15.6 & 5.6 & 64.10 \\
\hline 5 & S-653/ 32 & 52 & 20.8 & 60 & 16.6 & 11.6 & 30.12 & 27.4 & 4.2 & 84.67 \\
\hline 6 & $\begin{array}{l}\text { BRRI dhan } \\
40\end{array}$ & 40.8 & 19 & 53.43 & 16.4 & 10.8 & 34.14 & 9.6 & 4.4 & 54.16 \\
\hline 7 & $\begin{array}{l}\text { PBRC(STL) } \\
-20\end{array}$ & 43.4 & 21.8 & 49.76 & 14.2 & 10.6 & 25.35 & 11.4 & 4.6 & 59.64 \\
\hline 8 & S-604/ 32 & 46.8 & 21.8 & 53.41 & 14.4 & 9.8 & 31.94 & 15.6 & 3.2 & 79.48 \\
\hline 9 & S-530/ 32 & 46.8 & 27.6 & 41.02 & 14.2 & 12 & 15.49 & 12 & 6.4 & 46.66 \\
\hline 10 & S-603/32 & 39.2 & 22.6 & 42.34 & 11.2 & 8 & 28.57 & 11 & 5.4 & 50.90 \\
\hline 11 & S-445/32 & 45.4 & 25.6 & 43.61 & 13.2 & 10.8 & 18.18 & 13.8 & 5.2 & 62.31 \\
\hline 12 & S-635/ 32 & 41 & 18.6 & 54.63 & 13.2 & 8 & 39.39 & 9.4 & 3.6 & 61.70 \\
\hline 13 & S-375/32 & 40.8 & 26.2 & 35.78 & 16.4 & 11.4 & 30.48 & 10.4 & 6.6 & 36.53 \\
\hline 14 & S-731/ 32 & 45.2 & 27 & 40.26 & 14.6 & 9.8 & 32.87 & 15.6 & 6.6 & 57.69 \\
\hline 15 & $\begin{array}{l}\text { PBRC(STL) } \\
-15\end{array}$ & 43.8 & 28.2 & 35.61 & 12.8 & 11 & 14.06 & 14.6 & 7.4 & 49.31 \\
\hline 16 & Horkuch & 58.4 & 45.8 & 21.57 & 14.4 & 12.4 & 13.88 & 17.2 & 12.8 & 25.58 \\
\hline 17 & PBSAL-613 & 42.8 & 33.4 & 21.96 & 13 & 12 & 7.69 & 17 & 13.4 & 21.17 \\
\hline 18 & S-478/ 32 & 53 & 38.8 & 26.79 & 12.4 & 11.1 & 10.48 & 16.6 & 11.6 & 30.12 \\
\hline 19 & $\begin{array}{l}\text { Charnock } \\
\text { (DA-6) }\end{array}$ & 45.2 & 27 & 40.26 & 16.2 & 11 & 32.09 & 11.4 & 4.6 & 59.64 \\
\hline 20 & S-608/ 32 & 45.6 & 24.5 & 46.27 & 13.2 & 9.4 & 28.78 & 14.8 & 5 & 66.21 \\
\hline 21 & PBSAL-656 & 44.4 & 27.2 & 38.73 & 13.4 & 10 & 25.37 & 19 & 8.6 & 54.73 \\
\hline 22 & S-633/32 & 52 & 23.8 & 54.23 & 11.8 & 9.6 & 18.64 & 16 & 4.2 & 73.75 \\
\hline 23 & Binadhan-6 & 36.8 & 15 & 59.23 & 13.6 & 8.4 & 38.23 & 7.8 & 2.2 & 71.79 \\
\hline 24 & PBSAL-614 & 47 & 35.8 & 23.82 & 12.6 & 11 & 12.69 & 15.4 & 12.8 & 16.88 \\
\hline 25 & STM-1 & 45 & 23.8 & 47.11 & 13.4 & 11.4 & 14.92 & 11.2 & 5.2 & 53.57 \\
\hline 26 & PBSAL-730 & 46.4 & 33.8 & 27.15 & 16.2 & 14 & 13.58 & 15 & 11.2 & 25.33 \\
\hline 27 & Pokkali & 58.2 & 45.4 & 22 & 14.2 & 13 & 8.45 & 17.11 & 13.80 & 23.5 \\
\hline 28 & Iratom-24 & 44.6 & 23.6 & 47.08 & 17 & 12.4 & 27.05 & 20 & 2.8 & 86 \\
\hline$\% \mathrm{C}$ & & 11.65 & 27.78 & 28.31 & 13.32 & 14.88 & 43.11 & 32.70 & 51.56 & 35.41 \\
\hline Rar & & $\begin{array}{l}58.4- \\
39.2\end{array}$ & 45.8-15 & $\begin{array}{c}60- \\
21.57\end{array}$ & $\begin{array}{l}18.6- \\
11.2\end{array}$ & $14.8-8$ & $\begin{array}{l}43.95- \\
8.45\end{array}$ & $\begin{array}{l}27.4- \\
9.4\end{array}$ & $\begin{array}{l}14.2- \\
2.2\end{array}$ & $\begin{array}{c}86- \\
16.88\end{array}$ \\
\hline
\end{tabular}

Highest plant height reduction (60.5\%) was observed in the variety Iratom-24. On the other hand, lowest plant height reduction was observed in Horkuch (21.57 \%) followed by PBSAL-613 (21.96\%), Keshrail (22.06\%), Pokkali (22\%) and PBSAL-614 (23.82\%). These results indicated that plant height reduced under the salinity stress. Such types of results were also found by several researchers (Javed et al., 2006; Maiti et al., 2006). They showed that the increase in salinity level reduced the seedling height. Munns and Tester (2008) also reported that salinity might directly or indirectly inhibit cell division, consequences leaves and stems of the affected plants become stunted. 
Root growth also retarded by the salinity stress. At this study, several genotypes showed higher root length reduction. S-611/32 showed highest root length reduction (43.95\%) followed by Iratom-24 (43.80), S-635/32 (39.39\%), Binadhan-6 (38.23\%) and BRRIdhan 40 (34.14\%) (Table 8).On the other hand PBSAL-613 showed lowest root length reduction (7.69\%). Some rice genotypes also showed lower root length reduction viz. Pokkali (8.45\%), S-478/32 (10.48\%), PBSAL-614 (12.69\%), and Horkuch (13.88\%). The result showed that root length decreased under salinity stress. Maiti et al. (2006) found a considerable amount of genetic variation under saline condition at the seedling stage with reference to the variables such as root length, shoot and root dry weight. Roy et al. (2002) reported that number of roots plant ${ }^{-1}$ decreased with the increasing levels of salinity. Rodrigues et al. (2002) reported that root length reduced due to the effect of salinity, which coincided with the present study.

Total dry matter (TDM) is an important trait to evaluate the performance of rice genotypes for salt tolerance. The highest TDM reduction found in Iratom-24 (86\%) followed by S-653/32 (84.67\%) and S-611/32 (80.91\%). The lowest TDM reduction was found in PBSAL-614 (16.88\%), followed by PBSAL-613 (21.17\%), Pokkali (23.5), PBSAL-730 (25.33\%) and Horkuch (25.58\%). Therefore, the genotypes PBSAL-614, Pokkali PBSAL-613, PBSAL-730, Horkuch, and S$478 / 3$ were found as tolerant based on lower percentages reduction of TDM at $12 \mathrm{dS} \mathrm{m}^{-1} \mathrm{EC}$ level of salt stress. Comparing with modified SES system, seven genotypes viz. Pokkali, Horkuch, PBSAL (STL)-15, PBSAL-656, PBSAL-730, PBSAL-656 and S-478/32 were also found tolerant under salt stress at the same EC level (Table 3).

From the above results, it can be said that TMD reduction increased under salt stress. J aved et al. (2006) reported that increase in salinity level reduced the fresh biomass and dry biomass. Roy et al. (2002) reported that reduction of dry biomass (\% TDM) increased with the increased of salinity level.

\section{Genotyping of salinity tolerance}

Identification of molecular markers tightly linked to salt tolerant genes can serve as landmarks for the physical localization of such genes facilitating marker assisted selection (MAS).

\section{Screening twenty eight rice germplasmss for salt tolerance using SSR markers}

In this experiment RM152, RM443, RM127, RM140, RM9, RM169, RM18 and RM21 primers were used for polymorphism survey of twenty eight rice germplasms. Out of these primers, three polymorphic SSR markers viz., RM127, RM443 and RM140 were shown highly polymorphic and these three markers were selected to evaluate 28 rice germplasms for salt tolerance. According to the phenotypic performance, Pokkali was considered as tolerant and Iratom-24 was considered as susceptible. The lines having similar banding pattern to Pokkali were considered as tolerant and similar to Iratom-24 were considered as salt susceptible and having both banding pattern (Pokkali and Iratom-24) were considered as moderately tolerant (Table 5).

In respect of primer RM127, 7 lines were found tolerant at salt stress. In the same reaction, 11 lines were moderately tolerant and 10 lines were susceptible with compared to the tolerant variety Pokkali and susceptible variety Iratom-24 (Fig. 1).

Nine lines were detected as tolerant, 10 susceptible and 9 moderately tolerant lines were found with compared to the tolerant variety Pokkali and susceptible variety Iratom-24 with the reaction with RM140 (Fig. 2).

With RM443, 8 tolerant lines were identified. In the same reaction, 11 saline susceptible lines and 9 moderately tolerant lines were also found with compared to the tolerant variety Pokkali and susceptible variety Iratom-24 (Fig. 3).

From the summarized Table 5 it is shown that seven lines viz. Horkuch, PBSAL-613, S-478/32, PBSAL-656, Pokkali, PBSAL (STL)-15 and PBSAL-730 were found as tolerant, five lines viz. Keshrail, S-546/32, S-530/32, S-603/32 and S$445 / 32$ were found moderately tolerant and nine lines viz. Iratom-24, S-653/32, S-731/32 BRRIdhan 40, S-604/32, S-635/32, S-612/32, Charnock (DA-6) and Binadhan- 6 were found as susceptible against all the tested markers. Three lines viz. S-611/32, PBRC (STL)-15 and STM-1 were found tolerant only with RM140 and one line PBSAL-614 was found tolerant with RM443. Five lines viz. S-611/32, S-375/32, S-608/32, PBSAL-614 and STM-1 with RM127, four lines viz. PBRC (STL)-20, S-375/32, S-633/32 and PBSAL-614 with RM140 and three lines viz. STM-1, PBRC(STL)-15 and S-611/32 with RM443 were found as moderately tolerant. PBRC (STL)20 was found moderately tolerant with RM127, RM140 \&RM443 and S-608/32 was found susceptible with both RM140 and RM443.

These three primers i.e. RM127, RM140 and RM443 showed polymorphisms in the studied twenty eight rice germplasms because they showed different banding patterns and discriminate tolerant lines from moderately tolerant and susceptible with relation to the 
tolerant variety Pokkali and susceptible variety Iratom-24. The SSR markers were also reported as highly polymorphic in IR29 $\times$ Pokkali for tagging salt tolerant genes (Islam, 2004; Niones, 2004). El-Refaee et al. (2006) also reported that $80 \%$ of the tested SSR primers showed polymorphic pattern in rice while they studied 272 SSR primers on nine rice genotypes. Sultana et al. (2007) found RD-2586, TBDB-100, PNR519 and Dhol Kochuri as tolerant; BRRIdhan 40 and Y-1281 as moderately tolerant regarding the marker RM115 and concluded that genotypic screening for salt tolerance using molecular marker is more trustworthy and effective. Islam et al. (2007) also identified the genotypes viz.
Pokkali, Jamainaru, horkoz and RT-STL33 as salt tolerant using the markers RM231 and RM24.

From the phenotypic data of twenty eight rice genotypes, based on SES and percentage TDM reduction PBSAL-614, PBSAL-613, PBSAL-730, Horkuch, S-478/3 and Pokkali were identified as salt tolerant rice genotypes whereas Iratom-24, S-653/32, S-611/32, S-604/32, S-633/32, Binadhan-6 and S-608/32 were identified as salt susceptible rice genotypes. Keshrail, S-611/32, S$546 / 32$, S-530/32, S-603/32, S-445/32, S375/32, PBSAL-614, STM-1 were identified as moderately salt tolerant rice genotypes.

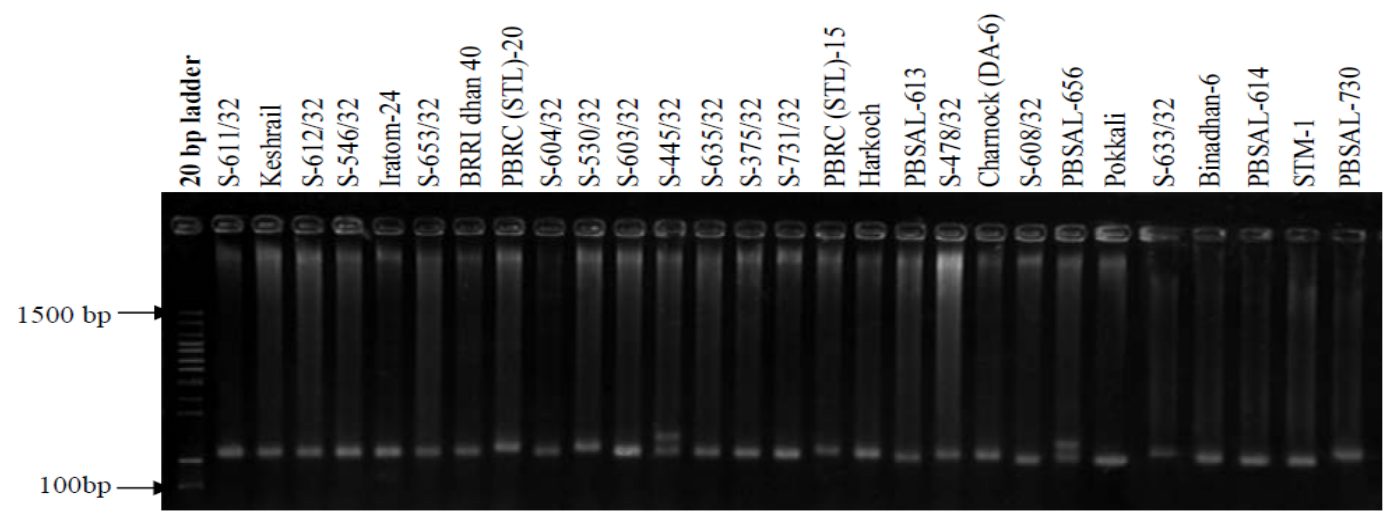

Fig. 1. Banding profiles of 28 rice germplasms using primer RM127

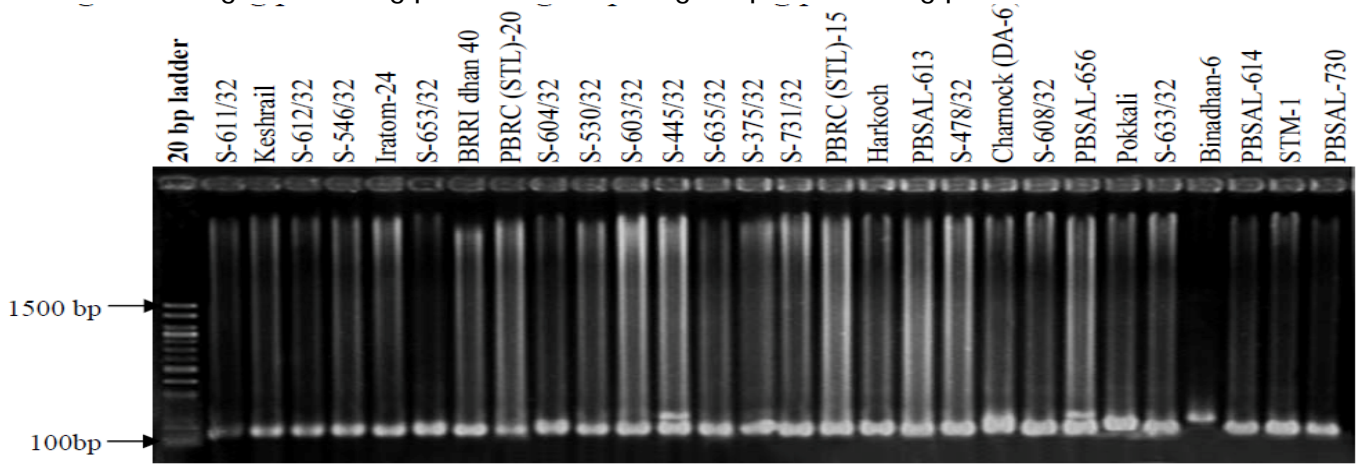

Fig. 2. Banding profiles of 28 rice germplasms using primer RM140

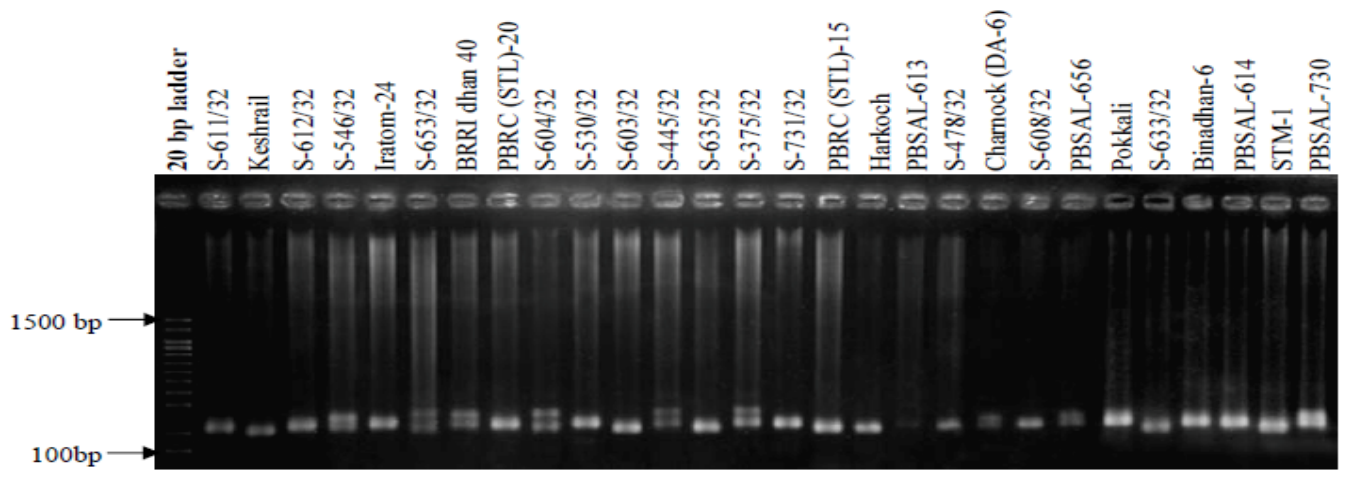

Fig. 3. Banding profiles of 28 rice germplasms using primer RM443 
Table 5. Genotypic performance of twenty eight rice germplasm using SSR markers

\begin{tabular}{|c|c|c|c|c|}
\hline \multirow[t]{2}{*}{ Sl. No. } & \multirow[t]{2}{*}{ Variety/ Line } & \multicolumn{3}{|c|}{ Salt tolerance with SSR markers } \\
\hline & & RM127 & RM140 & RM443 \\
\hline 1 & S-611/32 & MT & $\mathrm{T}$ & MT \\
\hline 2 & Keshrail & MT & MT & MT \\
\hline 3 & S-612/32 & $\mathrm{S}$ & $\mathrm{S}$ & $\mathrm{S}$ \\
\hline 4 & S-546/32 & MT & MT & MT \\
\hline 5 & S-653/32 & $\mathrm{S}$ & $\mathrm{S}$ & $\mathrm{S}$ \\
\hline 6 & BRRIdhan 40 & $\mathrm{~S}$ & $\mathrm{~S}$ & $\mathrm{~S}$ \\
\hline 7 & PBRC(STL)-20 & MT & MT & MT \\
\hline 8 & S-604/32 & $\mathrm{S}$ & $\mathrm{S}$ & $\mathrm{S}$ \\
\hline 9 & S-530/32 & MT & MT & MT \\
\hline 10 & $S-603 / 32$ & MT & MT & MT \\
\hline 11 & $S-445 / 32$ & MT & MT & MT \\
\hline 12 & S-635/32 & $\mathrm{S}$ & $\mathrm{S}$ & $\mathrm{S}$ \\
\hline 13 & S-375/32 & MT & MT & $\mathrm{T}$ \\
\hline 14 & S-731/32 & $\mathrm{S}$ & $\mathrm{S}$ & $\mathrm{S}$ \\
\hline 15 & PBRC(STL)-15 & $\mathrm{T}$ & $\mathrm{T}$ & MT \\
\hline 16 & Horkuch & $\mathrm{T}$ & $\mathrm{T}$ & $\mathrm{T}$ \\
\hline 17 & PBSAL-613 & $\mathrm{T}$ & $\mathrm{T}$ & $\mathrm{T}$ \\
\hline 18 & S-478/32 & $\mathrm{T}$ & $\mathrm{T}$ & $\mathrm{T}$ \\
\hline 19 & Charnock (DA-6) & $\mathrm{S}$ & $\mathrm{S}$ & $\mathrm{S}$ \\
\hline 20 & $\mathrm{~S}-608 / 32$ & MT & $\mathrm{S}$ & $\mathrm{S}$ \\
\hline 21 & PBSAL-656 & $\mathrm{T}$ & $\mathrm{T}$ & $\mathrm{T}$ \\
\hline 22 & S-633/32 & $\mathrm{S}$ & MT & $\mathrm{S}$ \\
\hline 23 & Binadhan-6 & $\mathrm{S}$ & $\mathrm{S}$ & $\mathrm{S}$ \\
\hline 24 & PBSAL-614 & MT & MT & $\mathrm{T}$ \\
\hline 25 & STM-1 & MT & $\mathrm{T}$ & MT \\
\hline 26 & PBSAL-730 & $\mathrm{T}$ & $\mathrm{T}$ & $\mathrm{T}$ \\
\hline 27 & Iratom-24 & $\mathrm{S}$ & $\mathrm{S}$ & $\mathrm{S}$ \\
\hline 28 & Pokkali & $\mathrm{T}$ & $\mathrm{T}$ & $\mathrm{T}$ \\
\hline
\end{tabular}

$\mathrm{T}=$ tolerant, $\mathrm{MT}=$ Moderately Tolerant and $\mathrm{S}=$ susceptible

Finally, salt tolerant rice lines were identified both phenotypically (salinity screening at the seedling stage) and genotypically using twenty eight rice germplasms. The tested markers RM127, RM140 and RM443 could be efficiently used to identify salt tolerant lines in rice and can also be used in marker-assisted selection (MAS) for breeding, quantitative trait loci (QTL) mapping, studying genetic diversity in germplasms and gene pyramiding in rice salinity breeding. Microsatellite marker analysis is promising to identify major gene locus for plant breeders to develop new cultivars. The selected salt tolerant rice lines could be further tested in saline areas to observe yield potentiality for developing high yielding salt tolerant varieties suitable for saline areas.

\section{References}

BBS. 2009. Crop Statistics (Major Crops). Agriculture Wing. Bangladesh Bureau of Statistics, Ministry of planning, Government of the People's Republic of Bangladesh, Dhaka. $54 \mathrm{p}$.

Bhuiyan, M.A.R. 2005. Efficiency in evaluating salt tolerance in rice using phenotypic and marker assisted selection. M.S. Thesis,
Department of Genetics and Plant Breeding, Bangladesh Agricultural University, Mymensingh, Bangladesh. 96 p.

Bonilla, P., Dvorak, J., Mackill, D., Deal, K. and Gregorio, G. 2002. RFLP and SSLP mapping of salinity tolerance genes in chromosome 1 of rice (Oryza sativa L.) using recombinant inbred lines. Philippine J. Agril. Sci. 85: 68-76.

El-Refaee, Y.Z, Atallah, M., Savo Sardaro, M.L. and Porceddu, E. 2006. Fine QTLs mapping for salinity tolerance in rice. Proceedings of the 50th Italian society of Agricultural Genetics Annual Congress. Ischia, Italy. ISBN 88-900622-7-4. pp. 10-14. Sep. 2006.

Gregorio, G.B. 1997. Tagging salinity tolerant genes in rice using amplified fragment length polymorphism (AFLP). Ph. D. dissertation. University of the Philippines Los Baños College, Laguna, Philippines. 118 p.

Gregorio, G.B., Senadhira, D. and Mendoza, R.D. 1997. Screening rice for salt tolerance. IRRI discussion paper series no. 22. Manila (Philippines). pp. 1-30.

IRRI (International Rice Research Institute). 1967. Annual Report. Los Banos. Laguna, Philippines. $308 \mathrm{p}$. 
Islam, M.M. 2004. Mapping salinity tolerance genes in rice (Oryza sativa L.) at reproductive stage. Ph.D. Dissertation. University of the Philippines Los Baños, College, Laguna, Philippines. $149 \mathrm{p}$.

Islam, M.M., Mondol, M.N.H., Emon, R.M., Begum, S.N., Bhowmik, S.K. and Hasan, A.K. 2007. Screening of salt tolerant rice genotypes using SSR markers at seedling stage. Bangladesh J. Prog. Sci. Tech. 5 (1): 45-48.

Javed, M.A., Ishii, T., Kamijima, O. and Misoo, S. 2006. Discrepancy of two ecotypes of Oryza sativa L. to salinity at germination and seedling stages. Ann. Biol. 22 (2): 201-211.

Kaddah, M.T., Lehman, W.F., Meek, B.D. and Robinson, F. E. 1975. Salinity effects on rice after boot stage. Agron. J. 67: 436-439.

Maiti, R.K., Vidyasagar, P. and Banerjee, P.P. 2006. Salinity tolerance in rice (Oryza sativa L.) hybrids and their parents at emergence and seedling stage. Crop Res. Hisar. 31 (3): 427-433

Munns, R. and Tester, M. 2008. Mechanisms of salinity tolerance. Ann. Rev. Plant Biol. 59: 651- 681.

Niones, J.M. 2004. Fine mapping of the salinity tolerance gene on chromosome1 of rice (Oryza sativa L.) using near-isogenic lines. M.S. Dissertation. University of the Philippines, Los Baños, College, Laguna, Philippines. $78 \mathrm{p}$.
Pearson, G.A., Ayers, S.D. and Eberhard, D.L. 1966. Relative salt tolerance of rice during germination and early seedling development. Soil Sci. 102: 151-165.

Rodrigues, L.N., Fernandes, P.D., Gheyi, H.R. and Viana, S.B.A. 2002. Germination and formation of rice seedlings under saline stress. Esc. Agrot. Fed. de Castanhal. 6 (3): 397-403.

Roy, S.K., Patra, S.K. and Sarkar, K.K. 2002. Studies on the effect of salinity stress on rice (Oryza sativa L.) at seedling stage. J. Interacademicia. 6 (3): 254-259.

Seraj, Z.I. and Salam, M.A. 2000. Growing rice in saline soils. : Biotechnological approaches for Bangladesh. Asia-Pacific Tech. Monitor. 17 (6): 55-59.

Sultana, S., Begum, S.N., Islam, M.M, Siddika, A., Bhowmik, S.K. and Emon, R.M. 2007. Identification of salt tolerant rice genotypes via microsatellite markers at the seedling Stage. Bangladesh J. Seed Sci. Tech. 11 (1\&2): 41-47.

Yoshida, S., Forno, D.A., Cook, J.H. and Gomez, K.A. 1976. Laboratory manual for physiological studies of rice. International Rice Research Institute, Los Baños, Laguna, Philippines. pp. 61-66. 